\title{
СТРАНОВЕДЕНИЕ РОССИИ В ПРАКТИКЕ ОБУЧЕНИЯ ГРУЗИНСКИХ УЧАЩИХСЯ РУССКОМУ ЯЗЫКУ НА НАЧАЛЬНОМ ЭТАПЕ
}

\author{
Хинчагашвили Н. Ш., Академический доктор филологии, ассои. проф. Горийского \\ государственного университета, г. Гори, Грузия.
}

\section{DOI: https://doi.org/10.31435/rsglobal_conf/25022021/7424}

Abstract. The article is dedicated to the possibility of the usage of the lingvo-oriented method for the Georgia students in the teaching of Russian as a foreign language. The aim of the article is to promote the enrichment of knowledge in the field of the Russian language through a dialogue of cultural meanings the presented linguo-and methodological culture oriented model of teaching Russian developed and based on communicative and interactive technologies gives the foreign students opportunity to learn about the culture of Russia and to use the acquired knowledge in the process of intercultural communication. The types of interactive exercises discussed in the article can also be used in the study of the history of Russian literature.

Keywords: Russian as a foreign language, cultural space, monument, communicative and interactive technologies, intercultural communication.

Введение. Новая технология обучения РКИ- ориентация на активное соизучение языка и культуры - суть современной методики преподавания иностранных языков. Овладение им предполагает приобщение обучаемого к другой культуре и участие в диалоге культур. В повседневной жизни прямой контакт между обучаемым и носителем изучаемого языка явление не такое уже и частое. Побывать же «в гостях» у другого народа или принять «в гости», чтобы оценить непохожесть и индивидуальность чужой культуры и языка, вполне возможно. Учесть эту возможность в практике обучения иностранному языку - первостепенная задача современного преподавателя.

Цель нашей работы заключается в разработке лингвометодологической модели обучения грузинских учащихся русскому языку как иностранному. В наше неспокойное время сочетание слов «диалог культур» в методике преподавания иностранных языков употребляют все чаще и чаще, хотя сама технология, в основу которой положены идеи М.М. Бахтина («о культуре как диалоге»), Л.С. Выготского (идея «внутренней речи»), В.С. Библера («философская логика культуры»), В.Н. Вагнера («лингвоориентированная методика») весьма актуальна. Диалог культур как двусторонняя информационная смысловая связь на сегодняшний день уже является важнейшим компонентом в процессе обучения иностранным языкам и является объектом исследования русистов, работающих в области методики преподавания РКИ. Хотелось бы отметить ряд работ Р.М. Теремовой в области межкультурной коммуникации.

Методы исследования. Разработанная нами методологическая модель позволяет познакомить грузинских учащихся со становлением и развитием различных видов русской и грузинской художественной культуры: архитектуры, монументальной скульптуры, музеев, географических и природных компонентов города/страны. Культурологическая доминанта является важным и неотъемлемым компонентом предлагаемой нами методологической модели: изучение русского как иностранного языка происходит посредством знакомства русской культуры через осмысление художественно-эстетической значимости достопримечательностей Грузии. Этот метод прекрасно проиллюстрирован в статье Р.М. Теремовой [5].

Результаты исследования. Предложенные учебные материалы выстроены на коммуникативно-интерактивной основе и предполагают активное взаимодействие преподавателя и обучаемых. Оно подразумевает использование монологических текстов (например, текстов информативного характера, текстов экскурсий, письма), диалогов с самыми разными видами заданий к ним, полилогов, блиц-опросов, дискуссий, круглых столов, клубов, конкурсов, ролевых игр. «Оживить» учебный процесс можно посредством использования иллюстративного материала: таблиц, рисунков, схем, фотографий. Предлагаем образец практического задания по тексту. 


\section{«Только нога ступила в Кавказ, я вспомнил, что я - грузин»}

Для Владимира Маяковского Грузия была больше, чем место, где он родился. Большой русский поэт всегда помнил своё родное село, грузинский язык и друзей детства.

В 1893 году в грузинском селе Багдади около города Кутаиси в семье лесника Владимира Маяковского родился третий ребёнок - сын Володя. В 1940 году, через 10 лет после смерти поэта, село назвали Маяковский, но в 1990 году ему возвратили старое название. В настоящее время тут находится Дом-музей Владимира Маяковского. Каждый год здесь отмечают день рождения поэта.

В 1902 году семья переехала в Кутаиси. Володя учился в Кутаисской классической гимназии №1. Сегодня в этом здании находится школа, а во дворе стоит памятник Маяковскому-гимназисту. Мальчик хорошо говорил по-грузински, любил читать, петь и рисовать, часто ездил с отцом в лес. Владимир был сильным и смелым мальчиком. Вместе с друзьями он любил купаться в быстрой горной речке Ханисцкали и однажды чуть не утонул.

В 1906 году после смерти отца семья переехала в Москву. Маяковский продолжил учёбу в Московском училище живописи, стал писать стихи.

Маяковский не забывал родину. В 1914 году он приезжал в Грузию, когда уже был известным поэтом. С группой русских поэтов читал свои стихотворения в Тифлисе и Кутаиси.

Следующая встреча с Грузией у Маяковского произошла в 1922 году в Париже. Поэту неожиданно повстречался грузинский друг - выдающийся художник Ладо Гудиашвили. Живописец позже вспоминал про этот случай: "Я сидел за чашкой кофе в кафе "Ротонда" на Монпарнасе. И вдруг слышу по-грузински "Гамарджоба, Ладо! Что ты здесь делаешь?" Мы обнялись, потом долго беседовали". [4]

Маяковский был талантливым человеком: он хорошо рисовал, писал в газеты и журналы, снимал фильмы, ставил спектакли по своим пьесам. В 1924 году поэт приехал в Тифлис, чтобы поставить пьесу, встречался с поэтами Т.Табидзе и С. Чиковани, художником К.Зданевичем, режиссером К.Марджанишвили. Друзья собирались во Дворце писателей, играли в бильярд, пили вино из Багдади.

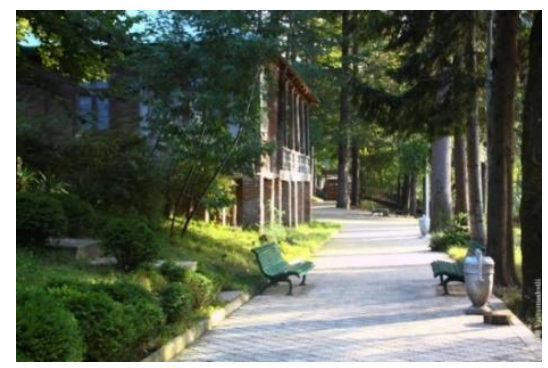

Рис.1. Дом-музей В.Маяковского в Багдади

Маяковский приезжал в Грузию ещё два раза - в 1926 и 1927 году. В театре имени Шота Руставели состоялся литературный вечер. Потом была встреча со студентами университета. А. Нуцубидзе вспоминал: "После чтения стихов - ответы на вопросы, среди которых часто звучали "Вы грузин или русский? Ваша Родина - Россия или Грузия?". Маяковский... улыбнулся и ответил: - Хотите знать, кто я? По рождению я грузин, а по национальности русский. Багдади - место моего рождения. Грузию люблю как родину, люблю ее небо, ее солнце, ее природу." [8]

Вечером, после литературных встреч, в кругу друзей поэт сидел в духане и пил грузинское вино. Тамадой была легендарная грузинская актриса Нато Вачнадзе.

Владимир Маяковский рано ушел из жизни. Ему было всего 36 лет. Но он остался в литературе, культуре, истории, в памяти поклонников его таланта и грузинской земли. В Багдади открыт Дом-музей поэта, а около него, у моста через речку, где любил купаться в детстве Володя, стоит его скульптура в полный рост (скульптор Георгий Кевхишвили). В Кутаиси, у здания кутаисской гимназии № 1 стоит памятник Маяковскому-гимназисту (скульпторы Валериан Мизандари и Георгий Николадзе). Самый большой бронзовый памятник Маяковскому установлен на одной из центральных улиц Тбилиси (скульптор Гурам Кордзахия). 


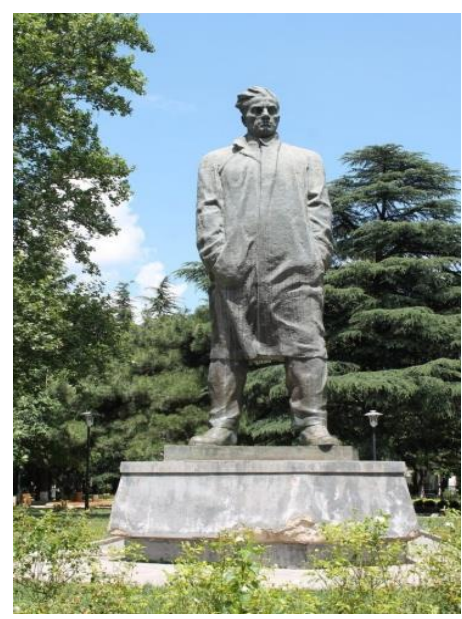

Рис. 2. Памятник В.Маяковскому в г.Тбилиси

Задание 1. Прочитайте текст и перескажите его.

Задание 2. Посмотрите на рис.1. Представьте, что к вам приехал друг, вы гуляете с ним и увидели этот домик. Какие вопросы может задать ваш друг? Как вы ответите на них? Составьте диалог.

Задание 3. Вам понравился дом, где родился поэт? Опишите его, используя слова и выражения из таблицы 1.

Таблица 1.

\begin{tabular}{|l|l|l|l|l|}
\hline \multicolumn{4}{|c|}{ Дом-музей имени В.Маяковского } \\
\hline \multicolumn{3}{|c|}{ какой? } & $\begin{array}{l}\text { большой/маленький } \\
\text { старый/новый } \\
\text { двухэтажный } \\
\text { кирпичный } \\
\text { деревянный }\end{array}$ \\
\hline \multirow{3}{|c|}{$\begin{array}{l}\text { в парке } \\
\text { в саду } \\
\text { в сквере } \\
\text { в зеленой } \\
\text { зоне }\end{array}$} & $\begin{array}{l}\text { есть } \\
\text { много }\end{array}$ & находится расположен & где? & $\begin{array}{l}\text { на площади } \\
\text { в центре города } \\
\text { в селе }\end{array}$ \\
\cline { 2 - 5 } & что? & $\begin{array}{l}\text { дом } \\
\text { скамейки } \\
\text { деревья } \\
\text { кусты }\end{array}$ & чей? & Маяковских \\
\hline
\end{tabular}

Задание 4. Посмотрите на рис.2. Ответьте на вопросы:

1. Сколько памятников В.Маяковскому стоят в Грузии?

2. Где находятся эти памятники?

3. Почему памятник Маяковскому-гимназисту стоит во дворе грузинской школы?

4. Где в Грузии установлен самый большой памятник поэту?

5. Как фамилия скульптора, который создал этот памятника?

Задание 5. Заполните таблицу, используя информацию из текста.

Таблица 2.

\begin{tabular}{|l|l|}
\hline даты & события \\
\hline 1893 & \\
1902 & \\
1906 & \\
1914 & \\
1924 & \\
1927 & \\
\hline
\end{tabular}


Задание 6. Ответьте на вопросы ДА/НЕТ

1. В.В. Маяковский - русский поэт

ДА/НЕТ

2. Будущий поэт родился в России

ДА/НЕТ

3. Село Багдади - место рождения В. Маяковского

ДА/НЕТ

4. Отец мальчика работал учителем

ДА/НЕТ

5. Маяковский учился в Кутаисской духовной семинарии

ДА/НЕТ

6. Семья Маяковских переехала жить в Тбилиси

ДА/НЕТ

7. В.Маяковский больше никогда не видел родину

ДА/НЕТ

8. В.Маяковский побывал в Грузии ещё четыре раза

ДА/НЕТ

9. В Грузии у Маяковского не осталось друзей и знакомых

ДА/НЕТ

10. Поэт прожил долгую жизнь

11. Память о большом русском поэту осталась в Грузии

ДА/НЕТ

12. Автор памятника поэту в Багдади Г. Кевхишвили

ДА/НЕТ

ДА/НЕТ

Т. о., лингвоориентированная методика обучения русскому языку как иностранному грузинских учащихся определяет общие лингвометодические положения, которые состоят в особой подаче языке нового явления и формирования навыков и умений употребления этого явления.

Выводы. Разработанная модель занятий, на наш взгляд, будет способствовать развитию общей культуры, обогащению знаний в области русского языка, развитию русской речи в условиях иноязычной среды. По-русски освещенная родная культура грузинского учащегося создаст доброжелательную атмосферу между ним и русским собеседником. Удачно подобранный учебный материал поможет грузинским учащимся осмыслить значительный пласт русской культуры и адекватно использовать полученные знания в различных ситуациях межкультурной коммуникации. В процессе приобщения к русской культуре грузинские учащиеся смогут более глубоко оценить культуру своей страны и активизировать навыки общения на русском языке.

Представленные в статье материалы занятия рассчитаны на учащихся, владеющих РКИ в объеме уровня А2-В1. Образец занятия можно использовать для самостоятельного изучения русского языка, и при изучении истории русской литературы как зарубежной.

\section{ЛИТЕРАТУРА}

1. Вагнер В.Н. Лингвоориентированная методика преподавания русского языка как иностранного. Традиции и новации в профессиональной деятельности преподавателя русского языка как иностранного: Учеб. Монография /Под общ. ред. С.А. Хаврониной, Т.М. Балыхиной. М., 2002

2. Лаперашвили В. Жизнь Маяковского в Грузии. Тб.,1961

3. Маяковскй в Грузии. Тб., 1936

4. Пипия Б. Великие в Грузии: от аргонавтов до Марадоны. Тб., 2011

5. Теремова Р.М. Спецкурс «Культурное пространство Санкт-Петербурга» в практике обучения иностранных учащихся русскому языку. «Русский язык за рубежом», № 2/2016.

6. Международный культурно-просветительский союз «Русский клуб». Возвращение. Владимир Маяковский в Грузии. Тб., 2008

7. Любовью за любовь. Памятники русской культуры в Грузии. Владимир Мааяковский (часть первая). Retrieved from http://korsovet.ge/ksorsg/maiak

8. Любовью за любовь. Памятники русской культуры в Грузии. Владимир Мааяковский (часть вторая). Retrieved from http://korsovet.ge/ksorsg/maiak-2 